\title{
THE DIAGNOSIS AND TREATMENT OF MYXOEDEMA
}

Richard Asher, M.D., F.R.C.P. Central Middlesex Hospital, London, N.W.io

I write on this subject as a physician more at home at the bedside than in the laboratory, but I feel justified in doing so because in this condition clinical methods are more helpful than laboratory tests.

Clinical diagnosis is made by examination and history-taking. Clinical proof is obtained by the results of treatment. Clinical encouragement (but occasionally clinical bewilderment) is obtained from laboratory tests.

\section{Diagnosis}

The first step in making a diagnosis is to think of it. That trite aphorism is so important in myxoedema that $I$ repeat it: The first step in diagnosing myxoedema is to think of it. When I wrote a few lines back that diagnosis was made by examination and history-taking, I deliberately put the two procedures in that order. With most diseases the history is more informative than clinical examination; myxoedema is an exception. The appearance and the voice of the patient often initiate the idea of the diagnosis before the history has suggested it. So it seems logical to start by describing the voice and appearance, and then discuss the history and the investigations.

With words alone it is impossible to convey the appearance or the voice of myxoedema with any success. The photographs convey more than the description I will attempt, and a gramophone record would give far more information about the voice. (As little plastic records are to-day cheap enough to be provided on greetings cards, it will not be long before a progressive journal provides a miniature disc on one of its pages.) However, a real live patient (or better still, several real live patients) would convey twice what this article can.

\section{The Appearance}

The first impression depends on whether you have seen the patient before. If you have known her for some years, but not seen her lately, you may have difficulty in recognizing her. When you do, you are struck by the change-she looks different and she looks older than you expected. She moves and talks more slowly, she is wearing more clothes than usual, and her face has a slightly oriental look; she has eyes which are narrowed by the surrounding swelling of the face. Her voice has become deep and thick and sounds as if her nose were blocked, indeed you may first think she has a bad cold. If the condition is advanced and the doctor experienced, he will find himself muttering under his breath as she enters-'Ah! ... Myxoedema!'

The appearance in an advanced case is unmistakable. The patient is usually a woman. Her face looks bloated, her eyes are narrowed, and her hair frowsy and scanty. She has clearly taken little interest in herself lately. Her skin has a waxy, parchment-like appearance which is often relieved by a burgundy-coloured flush over the cheeks. Her hair is very thin, and in severe cases there is partial baldness. The loss of hair is greatest at the front of the scalp, the hair margin recedes and the hair behind the margin is so thin that the scalp can be seen through the spaces. The eyebrows may lose a lot of hair too, but there is nothing diagnostic about losing the outer thirds, and many normal people show some thinness there. There may often be an inch or two of undyed hair at the roots, emphasizing the spiritual apathy which myxoedema causes. So metimes there are little pouches of oedema underthe eyes. These are more prominent on first waking in the morning; all types of swollen face seem to be worst then, probably the effect both of lying flat and of the absence of facial movements during sleep.

\section{The Voice}

The voice changes in character, depth and intonation; in milder cases the changes are likely to be interpreted as evidence of a chronic cold or ' catarrh.'

Women's voices may deepen so much they may be mistaken for men; I know of one lady who first realized that her voice must have changed 
when all her friends who telephoned her began to mistake her for her butler. As well as depth and huskiness the voice reveals nasal obstruction, being blocked by myxoedematous infiltration. Because the lips and tongue are swollen by myxomatous infiltration there is a fumbling quality of articulation which adds to the diagnostic ensemble. It is rather like a voice played on a gramophone whose motor is running down. (For modern Hi-Fi men, who have never wound a gramophone in their lives, the effect is similar to that produced by running a $7 \frac{1}{2} / \mathrm{sec}$. taperecording at $3 \frac{3}{4} / \mathrm{sec}$., or a 45 r.p.m. gramophone record at 33 r.p.m.) Also, the speaker sounds as if he had a bad cold, or was slightly drunk and had a large plum in the mouth (or a quinsy). The voice I have just described is only heard in moderately advanced cases; in gross cases, bordering on coma, the speech is almost incomprehensible, being punctuated by grunting sticky snorting sounds, which often persist even when the patient is not speaking. The breathing, too, is affected by the obstructed respiratory passages, and develops a laboured, grunting, animal quality. During sleep very loud snoring is often heard.

Though the face and the voice provide the bulk of evidence on which the diagnosis is based, further information is gained from the general demeanour, the skin, the neck and the heart.

\section{General Demeanour}

The patient with myxoedema thinks, talks and moves slowly. She may sleep much of the day, dropping off unintentionally whenever she sits down near the fire. If she is visited in bed she is likely to be found with most of her body covered by the bedclothes trying to get warm. I have seen several severe cases where nothing but the top of the patient's head could be seen, but this characteristic decubitus (the snug sign) is only found in quite advanced cases.

The skin is rough, dry and cold. With gross myxoedema in a patient bordering on coma the skin feels cadaverously cold with a reptiliform roughness which gives an unforgettable impression. The myxomatous infiltration of the skin gives to much of the body a spongy feel, something like foam rubber. I have only once seen enough myxomatous tissue above the clavicle to compose the classical supra-clavicular pads. The skin of the legs may show a combination of dependent oedema and myxoedema.

\section{The Neck}

When myxoedema is caused by atrophy and fibrosis of the gland, palpation of the neck reveals no palpable thyroid gland. It is quite difficult to feel the gland in normal people, so the absence of palpable thyroid tissue is not a finding which carries great weight in making the diagnosis.

Hashimoto's disease is also quite a commo cause of myxoedema. When a patient with myxoedema is found to have a smooth unusually hard goitre, this strongly suggests Hashimoto' disease, when auto-immune antibodies against thyroid substance are present (see under labora tory tests).

It seems unnecessary to mention that the sca of a thyroidectomy should be sought when there is evidence of myxoedema; but if the operation has been neatly performed, it is easy to miss, an $\Phi$ I have had a case of myxoedema referred $b \vec{y}$ quite an experienced physician with a thyroidec tomy scar which had not been noticed.

\section{The Heart}

Classically there is a slow pulse in myxoedema I have never found this a sign of much value $\vec{N}$ I have seen quite advanced cases of myxoedema with normal or raised pulse rates. I have seen several cases of myxoedema with bradycardia of $50 / \mathrm{min}$. or lower, but this has only occurred incases with such gross disease that there was n£ doubt about the diagnosis; all the doubt was related to the survival of the patient.

\section{History}

The history is less helpful than phystepep examination in making the diagnosis, but is of considerable value in confirming it. The symp toms are admitted to, rather than complained of and are discovered only when the right questions are asked. The relations notice the changes more than the patient, because the illness itself smothers self-criticism.

The following symptoms are common: General. tiredness and sleepiness, gain in weight, vague pains and paraesthesiae in the limbs, poo: memory, constipation, deafness, falling out of the hair, dryness of the skin, and feeling alwaysi cold. When the patient herself describes hers symptoms she rarely particularizes these, but includes them in a vague generalized statement such as 'I don't know what's come over me at all. I oughtn't to be like this. It's not me at all They all say at the office, "What's come overo you, Mabel, you're getting just like an old̆ toad!",

In asking about individual symptoms the doctor must avoid questions which veer towards the answer he wants. His enquiries must have no bias, or, if this is unavoidable, they should bes directed towards the wrong answer. One clear contradiction is worth five dutiful assents.

The history may come from relatives who are more aware than the patient of the changes that 


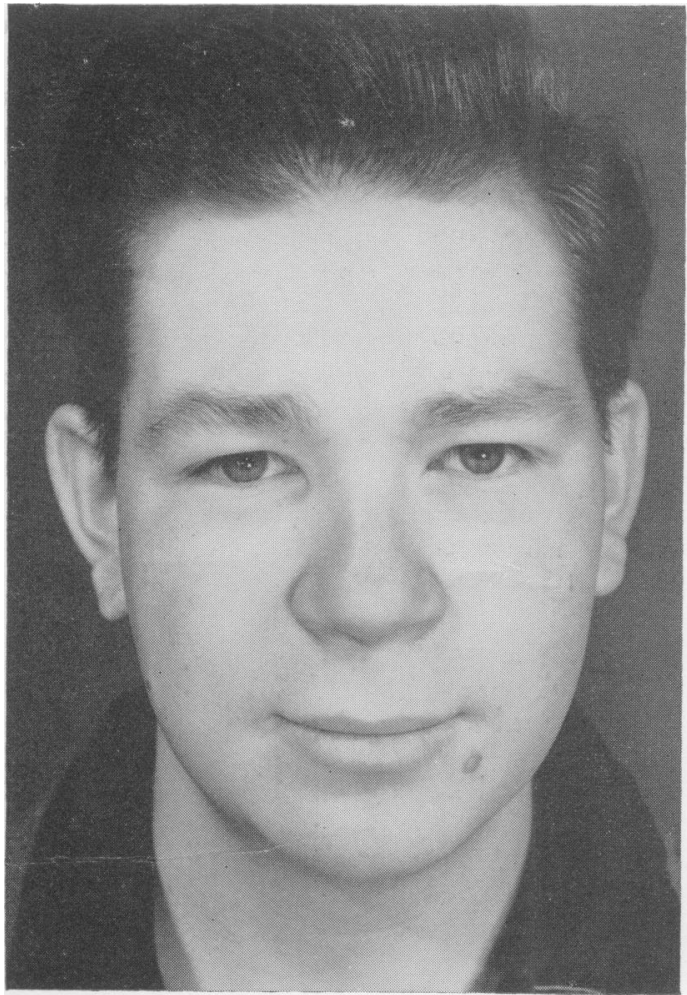

A

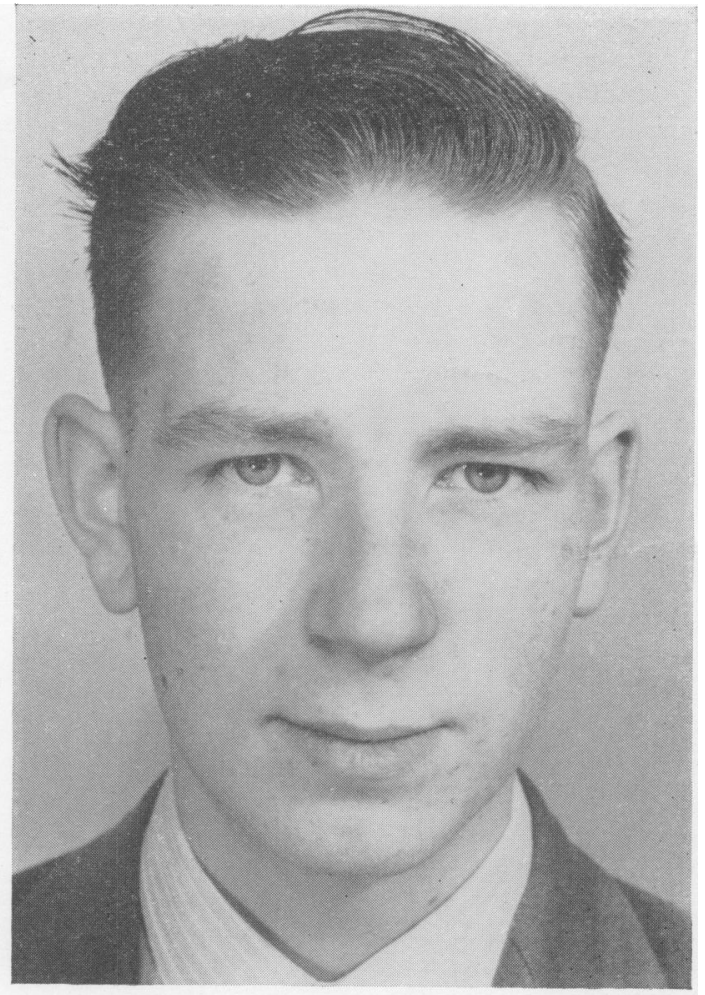

B

Fig. I.-Mild myxoedema. (a) Before treatment (January I, I957). The patient had presented with one year's

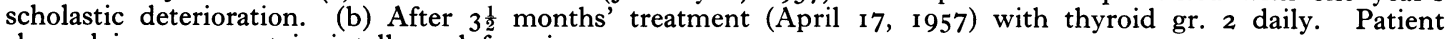
showed improvement in intellectual function.

have been taking place in her. It may be only a casual remark which starts the idea of the right diagnosis in the clinician's mind: 'Mother would go to bed with all her clothes on if she was given half a chance, and two overcoats as well,' or, 'She sits in front of the fire all day, she always seems to be dozing off.' Twice I have heard a lay relation suggest the right diagnosis because she had met the disease previously, e.g. 'Doctor, I suppose it couldn't be anything to do with her thyroid could it ? There was a lady next to me when I was in hospital what looked just the same as she does. They said she hadn't enough thyroid or something.'

Remarks of this kind may switch on the mental machinery for considering myxoedema, depending on recent experience. If you have seen myxoedema present as scholastic failure, " $\mathrm{He}$ was doing wonderful at school, they give him a scholarship, but now he don't seem to care, and he's gone all sort of dopey - - then any mention of dwindling scholastic powers will alert you to the possibility of myxoedema.

Though mental slowing down, loss of memory and general apathy are the commonest mental symptoms of myxoedema, it is not rare for gross psychotic change to occur, and the patient may become quite 'mental.' In 17 years, in charge of the mental observation ward at the Central Middlesex Hospital, I have seen over 25 cases of myxoedema sent in under the Lunacy and Mental Treatment Acts, and the mental symptoms have usually responded quickly to treatment with thyroid. It was the frequent arrival of patients with myxoedema who had been diagnosed as suffering from serious mental illness which first led me towards endocrinology. That hypothyroidism can cause insanity has been known for many years. A special commission appointed to look into the features of myxoedema reported in $\mathrm{I} 888$, 'delusions and hallucinations occur in nearly half the cases, mainly where the disease is advanced.'1 A popular novel by a doctor written in 1937 gives a sensational account of a mad patient cured by thyroid, ${ }^{2}$ which the author told me was based on his experience while working in a mental hospital. ${ }^{3}$ Thus the diagnosis of myxoedema has to be borne in mind by psychia- 


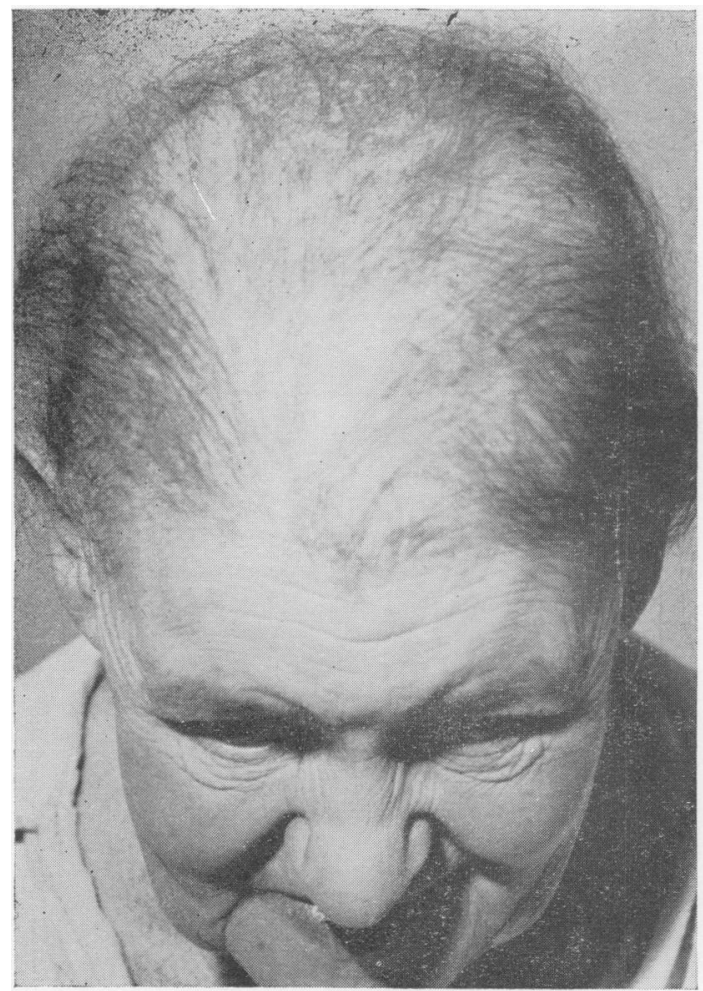

A

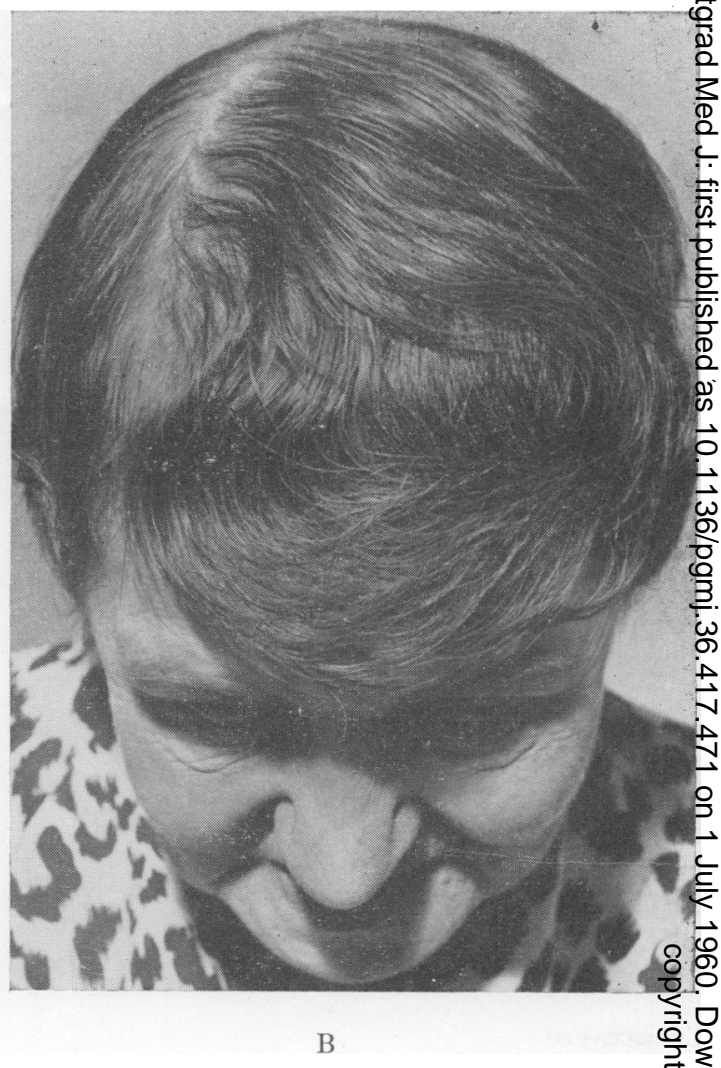

FIG. 2.-Moderately severe myxoedema. (a) Before treatment (December 22, 1958). (b) After four months, thyroi@
2 gr. daily (April 30, 1960). This patient was sent in with a severe confusional paranoid psychosis which respo.ded, dramatically to thyroid treatment.

trists as well as physicians. In truth there is no specialty to which myxoedematous symptoms may not bring the patient - to the gynaecologist with menstrual disorders, to the E.N.T. consultant with voice changes or deafness or to the surgeon with acute intestinal obstruction. This last complication, due to the constipation of myxoedema plus the myxomatous infiltration of the gut, produces gross abdominal distension; it responds quickly to thyroid treatment.

\section{Laboratory Investigations}

The diagnosis of myxoedema can usually be made on clinical grounds and confirmed by the effects of treatment. It is important to keep a record of the change by photographing the face before and after treatment, and also recording the weight (a tape-recording of the voice before and after treatment is also valuable). Other laboratory tests, except in special institutions, rarely contribute more than clinical assessment. The blood cholesterol is usually raised above $300 \mathrm{mg}$. $/ 100 \mathrm{ml}$. and descends to a level below $200 \mathrm{mg} . / 100 \mathrm{ml}$. after treatment. The basal metabolic rate should be less than minus $30 \% \frac{\varrho}{\overrightarrow{\overrightarrow{0}}}$ when symptoms appear and return to normal levels after treatment, but I have not used thie test for many years: I found I was accepting it when it agreed with the clinical picture ans disregarding it when it did not (which is nढे way to treat a laboratory report). The E.C.G - the dry skin makes good recording difficulto There may be bradycardia and a low voltage of the QRS complex with flattening or invero sion of the $\mathrm{T}$ wave. These changes resolves after thyroid treatment. Radiography-the heare shadow is usually enlarged. Investigations ma reveal that much of the apparent enlargement is caused by a pericardial effusion. After treatmenf the return of the cardiac shadow to normal pro portions is striking. Radio-iodine studies-I shalf say little about these as there is a separate article on the subject in this journal. The urinary ex cretion of radioactive iodine is followed for $4{ }^{8}$ hours after a dose of Iouc. of $I^{131}$. The values in the 24-48-hour specimens are higher than norma because the thyroid gland's iodine requirement\$ are diminished in myxoedema. When myxoedem 
is due to an anti-thyroid drug, the thyroid gland becomes avid for iodine as soon as the drug (which has been denying it access) is stopped. Hence the paradox of a myxoedematous patient with an increased iodine consumption is found when a patient has been taking a drug (or using resorcinol ointment) which has been stopped on admission.

\section{Auto-immune Thyroid Antibodies}

The principle is that a suspension of thyroid gland substance is agglutinated by the patient's blood if his myxoedema is due to these antibodies. A convenient way of preparing the thyroid suspension is to shake it with sticky red cells (tannin makes them sticky, hence they are called tanned red cells). Blood containing thyroid antibodies will then clump these cells because they are coated with thyroid. This is the principle of the tanned red cell agglutination test for auto-immune thyroid antibodies. As not all cases of Hashimoto's disease show a goitre, it is worth doing this test in every case of myxoedema to decide which patients have Hashimoto's disease. Nevertheless, the treatment is the same whether they have or not. When there is a goitre in Hashimoto's disease, it disappears with thyroid treatment while the myxoedema resolves.

\section{Treatment}

Almost all cases of myxoedema, whatever the cause, or whatever the degree of clinical severity, respond quickly and satisfactorily to 2 gr. of thyroid daily by mouth. To bring the average case back to good health costs less than sixpence (which is the price of 100 thyroid tablets), and it is one of the best bargains in medicine. For many years I have treated all my hypothyroid patients with ordinary B.P. Thyroideum Siccum, despite the availability of the pure synthetic crystalline hormone. Yet during the last year I have changed over to the synthetic hormone because the relapse of two patients on thyroid siccum gave me reasonable grounds for suspecting that some batches of thyroid tablets might be inactive. If the slightest doubt arises whether the tablets contain the necessary amount of hormone, it seems reasonable to give the pure hormone itself, about which there are no doubts. Despite my suspicions, I think it probable that 2 gr. of thyroideum siccum is nearly always as effective as $0.2 \mathrm{mg}$. of 1-thyroxine sodium-which is its pharmacological equivalent. Just to dispel that slight shadow of doubt I use now a tablet of 1-thyroxine sodium $0.2 \mathrm{mg}$. daily for both the therapeutic and maintenance treatment of myxoedema.

It is necessary to say here a word about main-

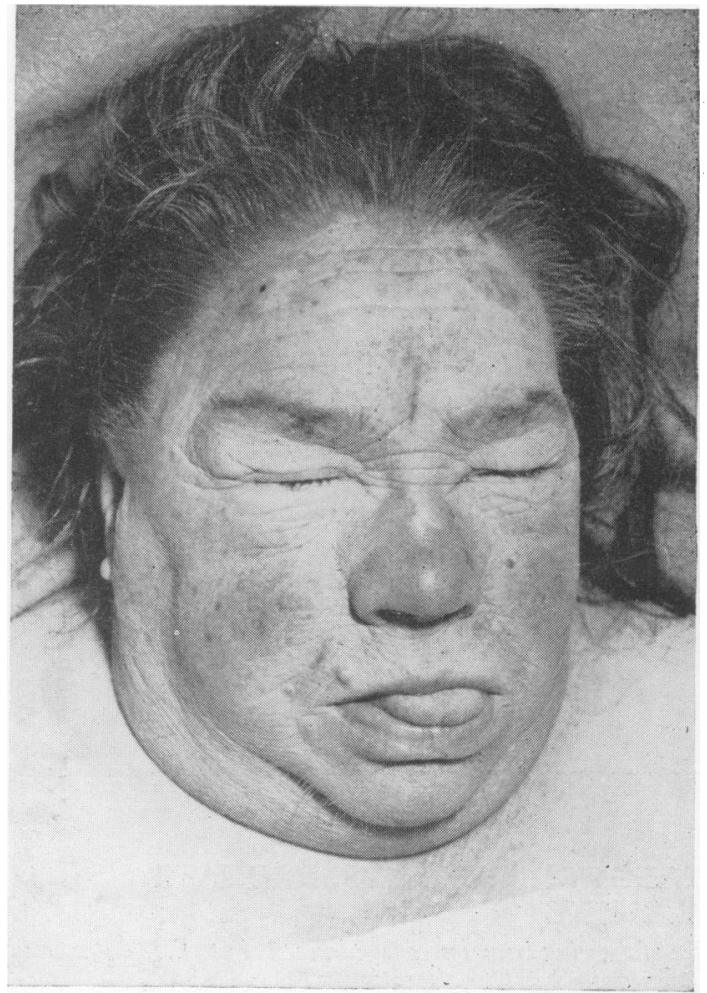

FIG. 3.-Gross myxoedema with myxoedema coma. There is no dramatic ' after treatment' picture here. coma, she died soon after admission.

tenance and the need to prevent the patient from relapsing by her stopping treatment. Most patients think illnesses are brought about by the presence of something wrong and not by the absence of something right. That is why they are likely to stop treatment when they feel perfectly well, unless they have been carefully warned by their doctor. If they do stop taking the tablets, their relapse soon makes them so dull and forgetful that they are unlikely to start taking them again. It is therefore wise to exhort the patient strongly to continue the treatment indefinitely, and also to ask a younger member of the family to 'make sure that granny goes on taking her tablets' if the patient is old enough to be unreliable.

It is only in cases of advanced myxoedema, who are in coma or near it, that there are difficulties or uncertainties in the treatment. Once the stage of coma is reached the mortality is so depressingly high that it is almost impossible to lay down a confident therapeutic regime. Both high and low doses of thyroid are advocated; I have seen recoveries with both, but most cases 
die. Some physicians leave them to generate their own warmth gradually and others advocate heating them artificially, but so few of these gross cases recover that I have no right to make any dogmatic pronouncement on how to treat them. I have a notion that to leave them severely alone -unheated, unwashed and undisturbed, but giving thyroxine $0.2 \mathrm{mg}$. daily-gives them aso good a chance as any other elaborate regime.

\section{REFERENCES}

I. Committee of the Clinical Society of London (1888), Trans. clin. Soc., Supplement to Vol. $2 \mathrm{I}$

2. CRONIN, A. J. (1937), 'The Citadel.' London: Victor Gollancz $\vec{\exists}$ Ltd.

3. CRONIN, A. J. (1949), Personal communication.

\section{POSTGRADUATE NEWS}

\section{July 1960}

The information contained in this section is published by courtesy of the organizations concerns and no responsibility for any changes of detail or omissions can be accepted by the publishers. In all cases, applications for enrolment or further information should be made direct to the sponsors of the course.

\section{FELLOWSHIP OF POSTGRADUATE MEDICINE}

The following courses are planned but the dates and details are subject to alteration.

Plastic Surgery (F.R.C.S.). Week-end September ro and I I. All day Saturday and Sunday. Queen Mary's Hospital, Roehampton. Limited. Fee $£ 44$ s.

Orthopaedics (F.R.C.S.). Week-ends. September 17 and 18 , October 1, 2, 15 and 16 . Saturdays and Sundays. Rowley Bristow Orthopaedic Hospital, Pyrford. Fee EI5 I5s. (no entries accepted until syllabus has been published and circulated).

Surgery (F.R.C.S.). General and Genito-Urinary. September 19 to October 5. Mondays and Wednesdays at 5 p.m. Whittington Hospital, Archway Wing. Limited. Fee $£ 55 \mathrm{~s}$.

Obstetrics (D.Obst.R.C.O.G.). September 26 to October I. All day. West Middlesex Hospital, Isleworth. Limited. Fee $£ 66 \mathrm{~s}$.

Children's Diseases (D.C.H.). Week-end October 8 and 9. All day Saturday and Sunday. Princess Louise Kensington Hospital. Limited. Fee £4 4s.

Infectious Diseases (M.R.C.P.). October 6, 13, 20 and 27. Chadwell Heath Hospital. Limited. Fee $£ 33$ s. Clinical Medicine (M.R.C.P.). October $3 \mathrm{I}$ to December 2. Daily 5.30 to 8.30 p.m. (Saturdays 2 to 4 p.m.). Whittington Hospital, N.r9. Limited. Fee £29 8s. (no entries accepted until syllabus published and circulated). Please note that instruction arranged by the Fellowship of Postgraduate Medicine is open only to members (annual subscription, 2 Is.). No entries for courses are accepted in advance of the detailed syllabuses being published and circulated; postgraduates (whether members or not) are not automatically included in the mailing lists but must notify the Fellowship of Postgraduate Medicine, 60 Portland Place, London, W. I, if they wish to be sent syllabuses as published, and must specify the subjects in which they are interested. Information regarding courses can be obtained from the office daily between 10 a.m. and 5 p.m. (Mondays to Fridays). Telephone: Langham 4266.

\section{ROYAL COLLEGE OF SURGEONS OF ENGLAND}

The following courses will be held:

Clinical Surgery. During September and Octobef요, 1960. Fee £42. (Entries by May 31, 1960.)

Surgery Lectures and Clinical Conferences. During October, 1960. Fee $\oint_{15}$ i5s. Lectures onty £io ros.

Application for further information should be made toळ Mr. R. S. Fohnson-Gilbert, Assistant Secretary, Royal ${ }^{\mathbb{D}}$ College of Surgeons, Lincoln's Inn Fields, London, W.C.2.

SOCIETY OF APOTHECARIES OF LONDON

Diploma in Industrial Health (D.I.H.). The examinations are held in July and December each year. Diploma of Mastery of Midwifery (M.M.S.A.). The examinations are held in May and November each year For further information applications should be addressed to the Registrar, Society of Apothecaries, Black Friars: Lane, London, E.C.4.

\section{GENERAL DENTAL COUNCIL}

The Dental Postgraduate Bureau has issued three? booklets, as follows:

- Facilities for Dental Postgraduate Study in the United Kingdom and Ireland,' containing a list of schools and institutions at which postgraduate courses are held or which provide facilities for individual students, and ano alphabetical list of subjects showing where instruction ${ }_{\omega}^{N}$ in each can be obtained; "Scholarships and Student- $O$ ships for Advanced Studies and Research in Dentistry, including many open to British subjects tenable abroad

' Higher Dental Qualifications,' setting out in general terms the conditions to be satisfied by candidates.

Copies of these booklets, particulars of films of interest to 0 dentists, and further information can be obtained ono application to the Registrar, General Dental Council, $\overrightarrow{\mathbb{D}}$ 37 Wimpole Street, London, W.r. 